Research, part of a Special Feature on Effects of Roads and Traffic on Wildlife Populations and Landscape Function

\title{
Impacts of Traffic Noise and Traffic Volume on Birds of Roadside Habitats
}

\author{
$\underline{\text { Kirsten M. Parris }}^{1,2}$ and $\underline{\text { Angela Schneider }}^{3}$
}

\begin{abstract}
Roadside habitats are important for a range of taxa including plants, insects, mammals, and birds, particularly in developed countries in which large expanses of native vegetation have been cleared for agriculture or urban development. Although roadside vegetation may provide suitable habitat for many species, resident animals can be exposed to high levels of traffic noise, visual disturbance from passing vehicles, and the risk of collision with cars and trucks. Traffic noise can reduce the distance over which acoustic signals such as song can be detected, an effect known as acoustic interference or masking. Studies from the northern hemisphere show that the singing behavior of birds changes in the presence of traffic noise. We investigated the impact of traffic noise and traffic volume on two species of birds, the Grey Shrike-thrush (Colluricincla harmonica) and the Grey Fantail (Rhipidura fuliginosa), at 58 roadside sites on the Mornington Peninsula, southeastern Australia. The lower singing Grey Shrike-thrush sang at a higher frequency in the presence of traffic noise, with a predicted increase in dominant frequency of $5.8 \mathrm{~Hz} / \mathrm{dB}$ of traffic noise, and a total effect size of $209 \mathrm{~Hz}$. In contrast, the higher singing Grey Fantail did not appear to change its song in traffic noise. The probability of detecting each species on a visit to a site declined substantially with increasing traffic noise and traffic volume, with several lines of evidence supporting a larger effect of traffic noise. Traffic noise could hamper detection of song by conspecifics, making it more difficult for birds to establish and maintain territories, attract mates and maintain pair bonds, and possibly leading to reduced breeding success in noisy roadside habitats. Closing key roads during the breeding season is a potential, but untested, management strategy to protect threatened bird species from traffic noise and collision with vehicles at the time of year when they are most vulnerable to their impacts. Other management options include reducing the speed and/or volume of traffic on such roads to an acceptably low level. Ours is the first study to investigate the effect of traffic noise on the singing behavior of birds in the southern hemisphere.
\end{abstract}

Key Words: acoustic interference; ambient noise; bioacoustics; conservation biology; road ecology; signal design; traffic noise; vocal communication.

\section{INTRODUCTION}

Interest in the ecological effects of roads and the traffic they carry has increased over the past two decades (Forman and Alexander 1998, Trombulak and Frissell 2000, Forman et al. 2003, Slabbekoorn and Ripmeester 2008). These effects include the loss and fragmentation of habitat, injury and death of wildlife attempting to cross roads, pollution of air, water, and soil, and constraints on acoustic communication in areas affected by traffic noise. Many animals including insects, frogs, birds, and mammals communicate via acoustic signals. Birds use calls and songs to attract and bond with mates, defend territories from rivals, maintain contact with social groups, beg for food, and warn of danger from approaching predators (Collins 2004, Marler 2004). Acoustic interference, also known as masking, occurs when background noise reduces the distance over which a signal can be heard (the active space; Marten and Marler 1977). Birds use a variety of strategies to maximize the active space of their signals in naturally noisy habitats (Brumm and Slabbekoorn 2005). However, those that live near

\footnotetext{
${ }^{1}$ School of Botany, University of Melbourne, Australia, ${ }^{2}$ Australian Research Centre for Urban Ecology, Royal Botanic Gardens Melbourne, Australia,

${ }^{3}$ Department of Zoology, University of Melbourne, Australia
} 
roads must also compete with traffic noise, much of which occurs in the low-frequency bands below $2000 \mathrm{~Hz}$ (Patricelli and Blickley 2006, Warren et al. 2006). Because energy in the spectral region of an acoustic signal contributes more to masking than does energy remote from the signal (Egan and Hake 1950), low-frequency signals are expected to suffer greater acoustic interference from traffic noise than are high-frequency signals.

Most research to date on the impact of traffic noise on wildlife has focused on birds in the northern hemisphere (but see Sun and Narins 2005, Bee and Swanson 2007). A range of behavioral responses to urban noise has been observed, including singing at a higher frequency (pitch), thereby reducing acoustic interference from the low-frequency noise (a frequency shift; Slabbekoorn and Peet 2003, Fernández-Juricic et al. 2005, Slabbekoorn and den Boer-Visser 2006, Wood and Yezerinac 2006); singing more loudly (an amplitude shift; Brumm 2004); and changing diurnal singing patterns to avoid peak traffic periods (a temporal shift; Fuller et al. 2007). Traffic noise may also affect bird populations and communities (Katti and Warren 2004). Reijnen et al. (1995, 1996) suggested that the lower population densities of birds in habitats close to roads in The Netherlands were caused by traffic noise, although these results may be confounded with other differences among the noisy roadside sites and the quieter control sites away from roads. Traffic noise was also proposed as the primary cause of reduced breeding success in Willow Warblers (Phylloscopus trochilus) with territories close to busy roads; the males had difficulty attracting and maintaining a mate (Reijnen and Foppen 1994). Rheindt (2003) hypothesized that birds with lowfrequency calls or songs would be less abundant at sites with high levels of traffic noise because they would experience greater acoustic interference from low-frequency noise. In an unreplicated study, Rheindt (2003) found some evidence that species with lower frequency signals were less abundant in noisy sites than they were in quiet sites.

Traffic volume and the number of vehicles traveling on an adjacent road could also affect birds in roadside habitats. The probability of a fatal collision with a vehicle is likely to increase with traffic volume (Clevenger et al. 2003), as will visual disturbance by passing cars and trucks. The impact of visual disturbance from passing vehicles on habitat suitability for birds is poorly understood (Goosem 2007), but could include avoidance of roadside areas for foraging and/or nesting, or reduced breeding success. Because both the level of traffic noise and the frequency of visual disturbance from passing vehicles increase with traffic volume, their effects are difficult to separate. However, Reijnen et al. (1995) controlled for the visibility of cars in their analysis of bird densities in woodland habitats adjacent to and distant from roads, and concluded that traffic noise had a greater effect on bird densities than did visual disturbance.

During the agricultural expansion of Australia, vast areas of native forest and woodland were cleared for pasture and crops. In many rural landscapes, much of the remnant vegetation is confined to narrow strips on public road reserves, forming a network of native habitat (Bennett 1991). Road reserves cover 567,000 ha $(2.5 \%)$ of the state of Victoria (Land Conservation Council 1988). They provide important habitat for many species of plants and animals, including the threatened Greycrowned Babbler (Pomatostomus temporalis), Squirrel Glider (Petaurus norfolcensis), and Brushtailed Phascogale (Phascogale tapaotafa)(Adam and Robinson 1996, van der Ree 2002, van der Ree et al. 2006). A recent study of bird communities of roadside remnants on the Mornington Peninsula, Victoria recorded 39 native species across eight transects (Antos and White 2004). Similarly, roadsides provide valuable habitat for plants, insects, birds, and mammals in the USA, UK, and Europe (Way 1977, Munguira and Thomas 1992, Bellamy et al. 2000, Saarinen 2005, Shochat et al. 2005). The use of roadside habitats by animals that communicate using acoustic signals, such as birds, presents an interesting trade-off between the presence of suitable habitat and the potentially detrimental effects of traffic noise and passing vehicles on survival rates, maintenance of territories, attraction of mates, and breeding success (Mumme et al. 2000, Warren et al. 2006).

In this study, we assessed the impacts of traffic noise and traffic volume on birds in narrow roadside strips of vegetation (road verges) in southern Australia using two target species; the Grey Shrike-thrush (Colluricincla harmonica; Pachycephalidae) and the Grey Fantail (Rhipidura fuliginosa; Dicruridae). Both species are common, sedentary, and dependent on forest, woodland, or shrubland (Higgins and Peter 2002, Higgins et al. 2006); thus, individuals that inhabit roadsides are expected to experience traffic noise and other disturbances from the adjacent road throughout the year. The two target 
species communicate using different parts of the frequency spectrum. The Grey Shrike-thrush sings at a lower frequency than the Grey Fantail, and therefore could be expected to suffer greater acoustic interference from traffic noise (Egan and Hake 1950, Warren et al. 2006). Our study sites were all located next to roads, but the roads ranged in size from narrow gravel roads with very little traffic to multi-lane freeways. This design reduced potentially confounding habitat differences between quiet and noisy sites. The study had two aims: (1) to assess the impact of traffic noise on song frequency in the Grey Shrike-thrush and the Grey Fantail, and (2) to investigate the effects of traffic noise and traffic volume on the probability of detecting each species on a single visit to a site. This is the first study to investigate the effect of traffic noise on the singing behavior of birds in the southern hemisphere.

\section{METHODS}

\section{Study area}

The Mornington Peninsula, southeast of Melbourne, Australia, is a temperate area that supports a variety of habitats including forest, woodland, coastal shrubland, and wetlands. The peninsula and adjacent Western Port Bay form a biosphere reserve that is part of the UNESCO Biosphere World Network. Extensive areas of the peninsula have been cleared for agriculture and residential development, and less than $15 \%$ of the original cover of native vegetation remains (Calder 1986). Large patches of remnant native vegetation are rare, so road reserves are an important part of the network of remnant habitats on the Mornington Peninsula.

\section{Study species}

The Grey Shrike-thrush is a medium-large bird with an average length of $25 \mathrm{~cm}$. The subspecies present in the study area, $C$. harmonica harmonica, inhabits a variety of forests, woodlands, and shrublands (Higgins and Peter 2002). Populations have reportedly declined following clearing for agriculture and urban development, but the species can persist in suitable patches of native vegetation within urban areas (Sewell and Catterall 1998, White et al. 2005). In addition, it is known to live and breed successfully on roadside strips of remnant woodland (Lynch et al. 1995, Antos and White
2004). The Grey Shrike-thrush is a sedentary species that remains in all-purpose territories throughout the year. Territories in large areas of habitat are thought to be $>5$ ha in size (Higgins and Peter 2002), but the size of territories in linear strips of habitat such as road reserves is uncertain. The species has a varied diet and forages at all levels from the ground to the canopy (Higgins and Peter 2002). Males sing to attract a mate, whereas both males and females sing to defend territories from neighbors. Mates sing in response to each other, and the species also uses a variety of alarm and distress calls (Higgins and Peter 2002). The song of the Grey Shrike-thrush is melodious and highly variable, containing pure tones, trills, and whistles (Fig. 1). Much of the acoustical energy in the song occurs in the frequency band between 1500 and $4000 \mathrm{~Hz}$.

The Grey Fantail is a small-medium bird with an average length of $15.5 \mathrm{~cm}$. The subspecies present in the study area, $R$. fuliginosa alisteri, commonly inhabits eucalypt forest and woodlands with a shrubby midstory, but is also known to occur in grassy woodland and coastal shrubland (Higgins et al. 2006). It can persist in roadside strips of vegetation in agricultural areas and in remnant patches of vegetation in urban areas, but it has not been observed in developed urban or suburban habitats (Antos and White 2004, White et al. 2005, Higgins et al. 2006). In Victoria, the Grey Fantail is considered to be a resident species, although a proportion of the population may migrate north during autumn (April-May) and return in late winter or early spring (August-September; Higgins et al. 2006). The species forages arboreally for invertebrates, usually at mid-levels of the forest or woodland. It defends all-purpose territories during the breeding season and throughout the year. Territory size is estimated at 1-2 ha in large areas of habitat (Higgins et al. 2006), but is unknown for linear strips of habitat such as road reserves. Adults use songs and calls for territorial advertisement, forming and maintaining pair bonds during courtship, incubation, and brooding, and to warn of danger from intruders or predators (Higgins et al. 2006). The characteristic adult song is a complex and variable sequence of high-pitched tones and frequency-modulated cheeps, both of which may include a series of harmonics (Fig. 2). Much of the acoustical energy in the song occurs in the frequency band between 4000 and $7500 \mathrm{~Hz}$. 
Fig. 1. Sonogram and power spectrum of a song of the Grey Shrike-thrush (Colluricincla harmonica), produced using Adobe Audition 2.0. The lowest tonal note is indicated with a circle and an arrow.
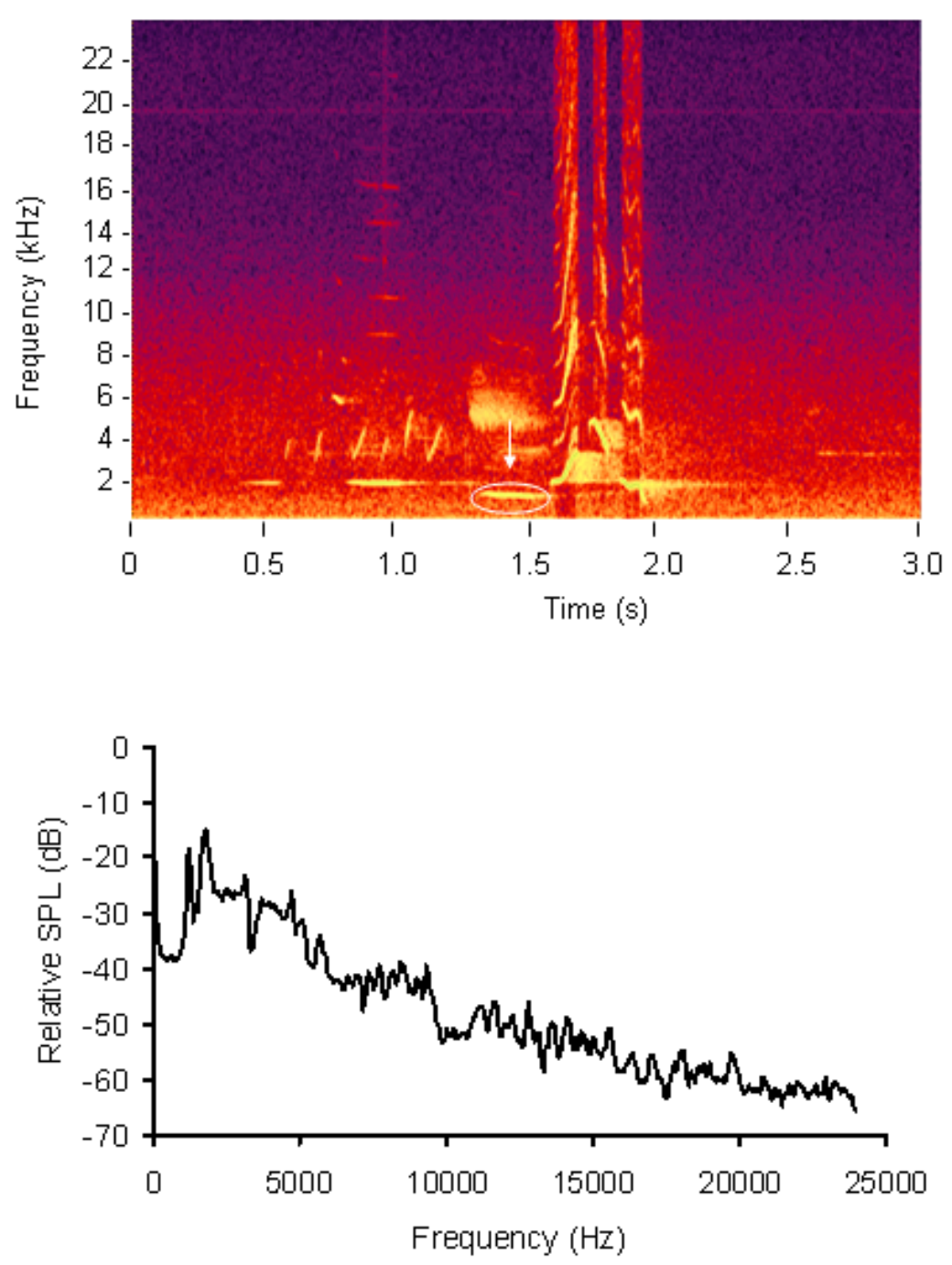
Fig. 2. Sonogram and power spectrum of a song of the Grey Fantail (Rhipidura fuliginosa), produced using Adobe Audition 2.0. The lowest tonal note is indicated with a circle and an arrow.
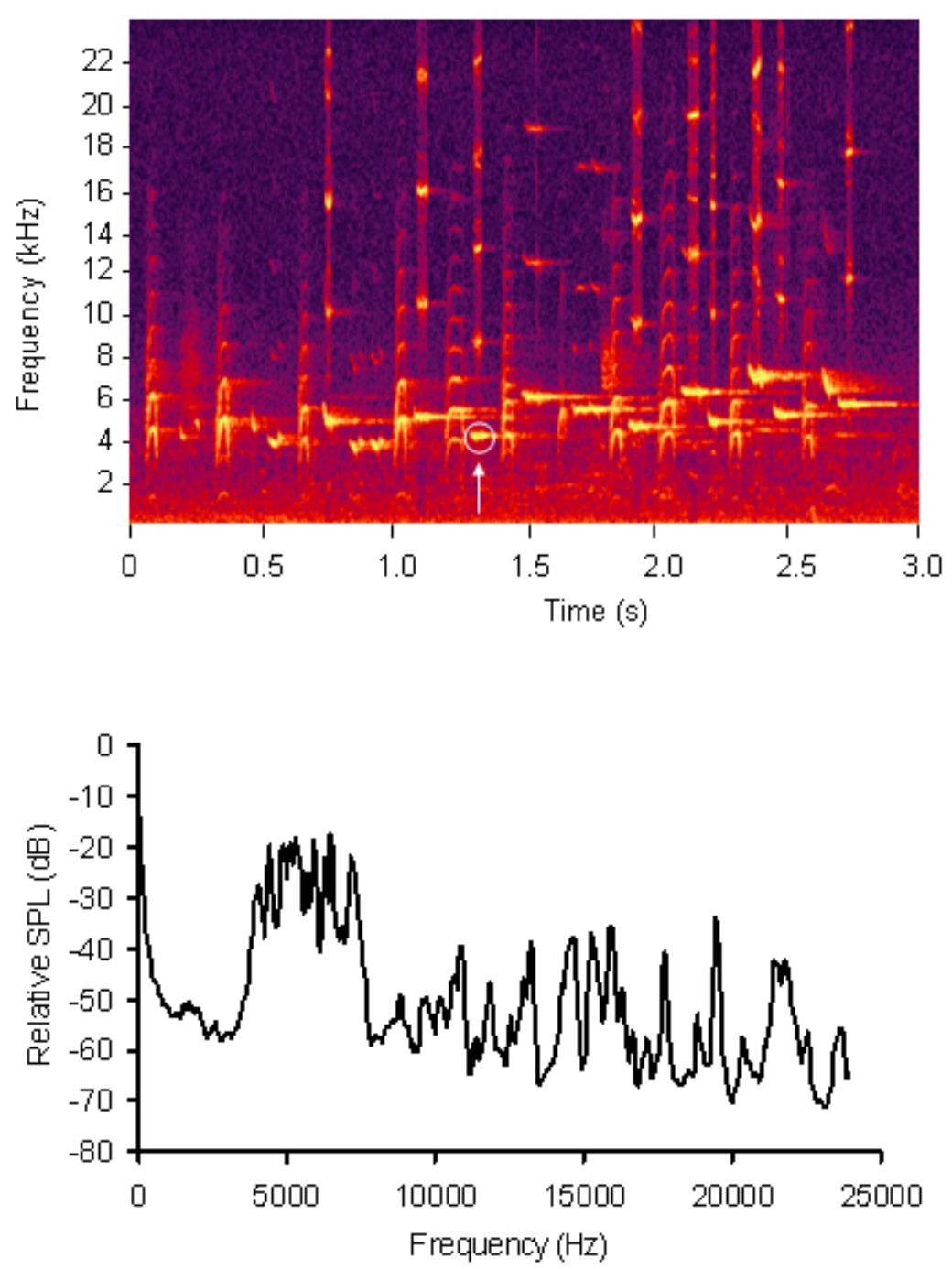


\section{Study sites}

We identified 58 study sites in narrow strips of roadside vegetation on the Mornington Peninsula using aerial photographs and a digital map of roads with the GIS program ArcView 3.2. The roads ranged in size from narrow, unsealed roads carrying fewer than 25 vehicles/d, to multilane freeways carrying 32,000 vehicles/d. The roadside vegetation at a given site was one of three types; shrubby Eucalyptus woodland (40 sites), grassy Eucalyptus woodland (7 sites), or coastal shrubland (11 sites). At the woodland sites, Eucalyptus obliqua, E. radiata, and $E$. viminalis pryoriana were the most common species in the overstory, with occasional intrusions of the exotic pine Pinus radiata. The midstory, when present, was typically composed of Acacia spp., Leptospermum spp., and/or Melaleuca spp., whereas the understory contained bracken Pteridium esculentum and a variety of native and exotic grasses and herbs. The coastal shrubland sites were dominated by Leptospermum spp. and/or Melaleuca spp., with Acacia spp. often present. The roadside strips of vegetation were $10-50 \mathrm{~m}$ wide, and occurred on one or both sides of the road. In addition, some dual carriageways had vegetation planted on the median strip. Each study site was 100 $\mathrm{m}$ long, parallel to the road, and included vegetation on each side of the road and the median strip, when present, up to a total width of $80 \mathrm{~m}$ (average $=42$ $\mathrm{m})$. The landscape context of the sites was either cleared agricultural land (rural), low-density residential development (suburban), or a combination of the two (rural-suburban fringe). The sites were located at least $1 \mathrm{~km}$ apart and at least $250 \mathrm{~m}$ from the nearest large patch of native vegetation. Data on the vegetation type and the width of the vegetation at each site, the landscape context of each site, and the distance to the nearest large patch of native vegetation were collated to assess the correlation between these variables and the traffic volume or level of traffic noise at a site. We did this to ensure that any observed relationships between the probability of detecting our target species and traffic noise and traffic volume were not confounded with other habitat differences between sites.

\section{Field sampling}

One researcher visited each site to survey for and record the songs of the target bird species during spring and summer (October 2005-February 2006 and September-October 2006). Birds were detected visually and by their song. Sites were visited more than once if a satisfactory recording was not obtained during the earlier visit(s), i.e., example, if there were unfavorable recording conditions, or if one of the target species was present but not singing. Four sites were visited for the first time rather late in the breeding season (December-February) when we suspected that singing activity had declined. These sites were visited again during the peak of the breeding season in October 2006. Recordings were made using a Marantz PMD670 portable solid-state digital recorder (Longford, UK) and a Sennheiser MKH 815T shotgun microphone (Wennebostel, Germany) with a basket windshield to reduce wind noise. The recordings had a sampling frequency of $48 \mathrm{kHz}$, and were made on dry, still days. When the target bird species were detected during a visit to a site, the researcher took up to six recordings of 1-5 minutes in length, depending upon the singing activity of the birds. All individuals singing at a site were recorded, whenever possible.

\section{Estimation of traffic volume and traffic noise}

Data on daily traffic volume and the percentage of heavy vehicles on a road were provided by local councils and the state road authority, VicRoads. In most cases, these data were in the form of exact numbers (e.g., 3500 vehicles/d). However, data for traffic volumes on some of the smaller, unsealed roads were only available in the categories $<200$ or 200-399 vehicles/d (Mornington Peninsula Shire 2006). For the purposes of our analysis, we converted these figures to 100 and 300 vehicles/d, respectively. For roads on which no traffic volume data were available, we used the median value for roads of that class on the Mornington Peninsula: 100 vehicles/d for local roads, 4000 vehicles/d for collector roads and secondary roads, and 7800 vehicles/d for main roads with a single carriageway. Six study sites were located on roads with estimated traffic volume data.

We estimated the level of traffic noise at each site using the calculation of road traffic noise (CoRTN) model (Department of Transport Welsh Office 1988). This model expresses noise levels as $L_{10} 18$ $\mathrm{h} \mathrm{dB}(\mathrm{A}) \mathrm{SPL}$, which is the 90th percentile of the distribution of traffic noise experienced in the $18 \mathrm{~h}$ from 0600 until $2400 \mathrm{~h}$. Thus, it estimates the level of traffic noise experienced by the birds throughout the day, using data on daily traffic volume, traffic speed, and percentage of heavy vehicles. We 
calculated the noise levels at each study site and along other nearby roads corrected for traffic speed, proportion of heavy vehicles, and distance. We then combined these values to give a single noise level for each site. We assumed that the gradient of all roads was $0 \%$, that traffic speeds were constant, and that the sources and reception points were at the same height. Following the CoRTN protocol, only roads with a traffic volume $\geq 50$ vehicles/h were included in the calculation (Department of Transport Welsh Office 1988). The estimated traffic-noise levels at the study sites ranged from 31 to $75 \mathrm{~L}_{10} 18 \mathrm{~h} \mathrm{~dB}(\mathrm{~A}) \mathrm{SPL}$. The CoRTN model estimates noise levels based on the hearing range, or audibility curve of humans, which is similar to the average audibility curve observed for birds (Dooling 2004).

\section{Analysis of songs}

We analyzed the recordings of the Grey Shrikethrush and the Grey Fantail with Adobe Audition 2.0 to determine the dominant frequency of the lowest tonal note of each song, using a BlackmanHarris window and a fast Fourier transformation (FFT) length of 1024. The dominant frequency of a note is the frequency containing the greatest amount of acoustical energy. The songs of the Grey Shrikethrush and Grey Fantail are complex and variable, containing tones, whistles, cheeps, and trills (Figs. 1 and 2). We selected the lowest tonal note, i.e., the lowest note with a consistent, narrow-band frequency, as the unit of analysis because tonal notes give a clear frequency signal, and because we expected the lowest notes of a song to suffer the greatest masking by the low-frequency traffic noise. The lowest tonal notes in each song were not necessarily homologous among songs or among individuals. We included all recorded songs of the target species in the analysis.

\section{Statistical framework}

The use of conventional statistical methods in ecology is problematic for a number of reasons (Johnson 1999, Anderson et al. 2000, McCarthy 2007). The null hypothesis chosen by researchers often makes no biological sense, the Type 1 error (alpha) is set arbitrarily, and statistical power is often ignored. Furthermore, ecologists commonly misinterpret the results of statistical tests, equating statistical significance with biological significance, and/or considering the absence of a statistically significant effect as evidence of no effect (Johnson 1999, Anderson et al. 2000, Fidler et al. 2006). Presenting effect sizes with some measure of variance or precision, such as confidence intervals, is generally more informative than presenting $P$ values alone, and enables the results of a study to be included in future meta-analyses (Anderson et al. 2000, Fidler et al. 2006). We used a Bayesian framework for our statistical analyses, with an emphasis on effect sizes and precision. In Bayesian statistics, estimates of parameters are described by posterior density functions or probability distributions, representing the uncertainty in the estimates. These posterior distributions are obtained by combining prior information, if it exists, with new data (McCarthy 2007). The Bayesian framework is well suited to analyzing hierarchical models that include random and fixed effects (Clark 2005), such as those used in this study.

\section{Effect of traffic noise on the frequency of bird song}

We estimated the effect of traffic noise on the dominant frequency of the lowest tonal note of each species' song using hierarchical, Bayesian multiple linear regression in OpenBUGS (Spiegelhalter et al. 2006, McCarthy 2007). The regression models included flat (uninformative) priors to reflect an absence of prior information, and a random site effect to account for variation in song frequency that was not explained by traffic noise. Using uninformative priors gives results that are numerically similar to those based on maximum likelihood estimation. The models also accounted for dependence between the songs recorded at a survey site, treating each song as a random sample of all possible songs at a site. We calculated the mean and standard deviation of the posterior distributions of the model coefficients, along with the 2.5th and 97.5th percentiles. This interval represented a 95\% Bayesian confidence interval (95\% credible interval). The standard deviation of the posterior distribution of an estimated parameter is the Bayesian equivalent of a standard error. We centered the explanatory variables (centered value $=$ the variable - its mean) to help reduce autocorrelation between successive samples obtained from the Markov chain Monte Carlo (MCMC) algorithm in OpenBUGS. To ensure that the models were sampling from the stationary distribution, we discarded the first 100,000 samples 
as a burn-in before taking 500,000 samples from the posterior distribution to estimate parameters. We checked stationarity by examining the history of samples obtained from OpenBUGS, and by running models with alternative initial values for the Markov chain.

\section{Effects of traffic noise and traffic volume on the probability of detection}

Across all 58 sites, we estimated the probability of detecting the Grey Shrike-thrush and Grey Fantail on a visit to a study site as a function of traffic noise and the daily volume of traffic on the road at a site using hierarchical, Bayesian logistic regression in OpenBUGS. As the values for traffic volume ranged over several orders of magnitude, we logtransformed these data before including them in the regression models. Even though multiple roads contributed to the level of traffic noise experienced by the birds at many of the sites, traffic noise and the traffic volume on the road at the site were correlated $\left(r^{2}=0.72\right)$. Consequently, we modeled their effects separately, and then assessed which model fitted the data best using the deviance information criterion (DIC; Spiegelhalter et al. 2002) and the area under the receiver-operating characteristic curve (AUC; Hanley and McNeil 1982, Wintle et al. 2005). We also managed to separate the effects of traffic noise and traffic volume by modeling the probability of detecting our two target species as a function of traffic noise at the 19 sites with a traffic volume of $<200$ vehicles/ d. The level of traffic noise at these sites was dominated by the noise from the nearest busy road, and ranged from an estimated 31 to $56 \mathrm{~L}_{10} 18 \mathrm{~h} \mathrm{~dB}$ (A) SPL. This enabled us to assess the impact of traffic noise while holding traffic volume at a low level.

DIC values reflect a trade-off between the fit of a model and its complexity, with smaller values indicating a better model. DIC values can be interpreted in a similar way to Akaike's information criterion (AIC) values (Burnham and Anderson 2002, Spiegelhalter et al. 2002). When comparing models, a difference of $<2$ between their DIC values indicates that they are largely indistinguishable. A difference $\geq 3$ indicates that the model with the smaller DIC value is probably superior. The AUC evaluates how well a model discriminates between sites at which a species was detected and those at which it was not, and therefore measures its predictive discrimination (Pearce and Ferrier 2000). The AUC ranges in value from 0 to 1 . A score of 1 corresponds to perfect discrimination, and a score of 0.5 indicates that the predictive discrimination of the model is no better than random (Bambar 1975). We calculated the DIC value and AUC for each model of the probability of detecting the Grey Shrike-thrush and Grey Fantail across all 58 sites in OpenBUGS.

Our logistic regression models included flat priors to reflect an absence of prior information, and a random site effect to account for variation in the probability of detecting the birds at a site that was not explained by traffic noise or traffic volume. That is, variation in the probability of detection related to characteristics of the habitat at a site, or weather conditions during a visit, was accounted for as long as these variables were not systematically correlated with traffic noise or traffic volume. This approach of minimizing the number of explanatory variables in a model and including a random site effect simplifies model interpretation and comparison (Burnham and Anderson 2002). As for the linear regression models described above, we calculated the mean and standard deviation of the posterior distributions of the model coefficients, along with the 2.5th and 97.5th percentiles. We centered the explanatory variables to help reduce autocorrelation between the successive samples obtained from the MCMC algorithm in OpenBUGS. To ensure that the models had attained the stationary distribution, we discarded the first 20,000 samples as a burn-in before taking 200,000 samples from the posterior distribution. Stationarity was checked by examining the history of samples obtained from OpenBUGS, and running models with alternative initial values for the Markov chain.

\section{RESULTS}

\section{Effect of traffic noise on the frequency of bird song}

During a total of 79 visits to 58 study sites, we detected the Grey Shrike-thrush at 27 sites and the Grey Fantail at 22 sites. We recorded 310 songs of the Grey Shrike-thrush and 116 songs of the Grey Fantail for acoustical analysis. Regression modeling indicated that the Grey Shrike-thrush sang at a higher frequency in traffic noise. The predicted increase in the dominant frequency of the lowest tonal note of a song was $5.8 \mathrm{~Hz} / \mathrm{dB}$ of traffic noise 
(95\% CI: -2.5, -14.5; Table 1; Fig. 3A). This represents an increase of $209 \mathrm{~Hz}$ or $14.2 \%$ over the range of the data, and a proportional increase of $0.39 \% / \mathrm{dB}$ of traffic noise. In contrast, there was little evidence of an increase in the frequency of the Grey Fantail song with increasing traffic noise, and the effect was predicted to be small. Regression modeling predicted an increase of $0.27 \mathrm{~Hz} / \mathrm{dB}$ of traffic noise (95\% CI: -8.1, - 8.5; Table 1; Fig. 3B). This corresponds to an increase of $11 \mathrm{~Hz}$ or $0.25 \%$ over the range of traffic noise levels observed, and a proportional frequency shift of $0.006 \% / \mathrm{dB}$ of traffic noise. However, the credible intervals around the mean effect were very wide (Fig. 3B), indicating a lack of precision in the data that could be improved with a larger sample size.

\section{Effects of traffic noise and traffic volume on the probability of detection}

The probability of detecting both the Grey Shrikethrush and the Grey Fantail on a visit to a site decreased with increasing traffic noise and increasing traffic volume. The louder the traffic noise or the greater the number of passing vehicles, the less likely we were to find the target bird species (Tables 2 and 3; Figs. 4 and 5). Across all 58 study sites, the predicted probability of detecting the Grey Shrike-thrush on a visit to a site ranged from 0.86 (95\% CI: $0.61,1.0)$ at the quietest site to $0.10(95 \%$ CI: $0.00,0.28$ ) at the noisiest site (Table 2, Model 1; Fig. 4A). This represents a decrease in the probability of detection (effect size) of 0.76 between the quietest and noisiest sites. The predicted probability of detecting the species ranged from 0.63 (95\% CI: 0.23, 0.93) at the sites with the fewest passing vehicles to 0.13 (95\% CI: $0,0.43)$ at the site with the most vehicles (Table 2, Model 2; Fig. 4B), with an effect size of 0.50 . The noisiest site at which we detected the Grey Shrike-thrush had an estimated traffic-noise level of $67 \mathrm{~L}_{10} 18 \mathrm{~h} \mathrm{~dB}(\mathrm{~A})$ SPL. The road at this site carried an estimated 4000 vehicles/d, the highest traffic volume at any site at which the Grey Shrike-thrush was detected. The wide credible intervals around the mean effects (Fig. 4) indicate a lack of precision, which could be improved with a larger sample size. The DIC values for the two models differed by $>3$ units, indicating that the traffic-noise model was probably superior to the traffic-volume model (Table 2). The AUC of the traffic-noise model was also superior to that of the traffic-volume model, indicating that the former had better discriminatory power (Table 2 ). Thus, all three lines of evidence (effect sizes, DIC values, and AUC values) support traffic noise as a more important influence than traffic volume on the probability of detecting the Grey Shrike-thrush in roadside habitats. Furthermore, when we restricted our analysis to the 19 sites with a traffic volume of $<200$ vehicles/d, the results were consistent with those of the model that included all 58 sites; the relationship predicted in Model 3 fell within the credible intervals of Model 1. This indicated that when the traffic volume at a site was held constant at a low level, there was still an important negative effect of traffic noise on the probability of detection (Table 2, Model 3).

The two models of the Grey Fantail across all 58 study sites yielded similar results to those of the Grey Shrike-thrush. The predicted probability of detecting the Grey Fantail on a visit to a site ranged from 0.71 (95\% CI: $0.43,0.94)$ at the quietest site to 0.10 (95\% CI: $0,0.27)$ at the noisiest site (Table 3, Model 1; Fig. 5A). The probability of detecting the Grey Fantail ranged from 0.52 (95\% CI: 0.25, 0.76 ) at the sites with the fewest passing vehicles to 0.11 (95\% CI: 0, 0.32) at the site with the most vehicles (Table 3, Model 2; Fig. 5B). The effect sizes for the two models were therefore 0.61 and 0.41 , respectively. The noisiest site at which the Grey Fantail was detected had an estimated trafficnoise level of $72.3 \mathrm{~L}_{10} 18 \mathrm{~h} \mathrm{~dB}(\mathrm{~A}) \mathrm{SPL}$, and the road at this site carried 13,700 vehicles/d. Again, wide credible intervals indicate a lack of precision in our data. The DIC values for the two models differed by $>3$ units, indicating that the traffic-noise model was probably superior to the traffic-volume model (Table 3). The AUC of the traffic-noise model was also superior to that of the traffic-volume model. As for the Grey Shrike-thrush, all three lines of evidence support traffic noise as the more important variable influencing the probability of detecting the Grey Fantail in roadside habitats. Furthermore, the probability of detecting the Grey Fantail as a function of traffic noise at the 19 sites with a traffic volume of $<200$ vehicles/d was consistent with that predicted by the analysis that included all 58 sites (Table 3, Models 1 and 3).

Neither the type of vegetation at a site, the width of vegetation at a site, nor the distance to the nearest large patch of remnant vegetation showed an important correlation with traffic volume or the level of traffic noise at a site $(r=-0.22,0.07)$. However, there was a moderate correlation between 
Table 1. Coefficients (mean, SD, and 2.5th and 97.5th percentiles) of the variables included in the models of song frequency (dominant frequency of the lowest tonal note) as a function of traffic noise.

\begin{tabular}{lllllllll}
\hline \hline & \multicolumn{3}{c}{ Colluricincla harmonica } \\
\hline Variable & Mean & SD & $\mathbf{2 . 5 \%}$ & $\mathbf{9 7 . 5 \%}$ & Mean & SD & $\mathbf{2 . 5 \%}$ & $\mathbf{9 7 . 5 \%}$ \\
Constant & 1583 & 52 & 1480 & 1687 & 4352 & 53 & 4248 & 4456 \\
\multirow{2}{*}{ Traffic noise } & 5.81 & 4.31 & -2.52 & 14.5 & 0.265 & 4.20 & -8.07 & 8.53 \\
\hline
\end{tabular}

traffic noise and landscape context (Spearman's $\rho$ $=0.53)$ and between traffic volume and landscape context (Spearman's $\rho=0.56$ ), because all three suburban sites were located on busy, noisy roads. To ensure that landscape context was not influencing the predicted relationships between the probability of detection of the target species and traffic noise or traffic volume, we re-ran our models, excluding the three suburban sites. These models were qualitatively identical to those that included all 58 sites, indicating that landscape context did not explain the decline in the probability of detection with increasing traffic noise or traffic volume.

\section{DISCUSSION}

\section{Effect of traffic noise on song frequency}

At sites at which the Grey Shrike-thrush occurred, the species sang at a higher acoustic frequency with increasing traffic noise. The predicted increase of approximately $200 \mathrm{~Hz}$ in the dominant frequency of its song between the quietest and noisiest sites would be clearly detectable by conspecific birds. This frequency shift would serve to increase the active space of an individual's song in traffic-noisy conditions, but is unlikely to fully compensate for the acoustic interference experienced. Thus, birds singing at a higher frequency in traffic noise would still achieve a smaller active space than birds singing at the baseline frequency in quiet conditions. Furthermore, the frequency shift observed for the Grey Shrike-thrush could reduce a bird's attractiveness to potential mates, as hypothesized for Great Tits Parus major (Slabbekoorn and Ripmeester 2008). However, preferences for lowfrequency song, as a potential indicator of larger body size or overall condition, have not been investigated in the Grey Shrike-thrush. The impact of a frequency shift in traffic noise on the ability to attract a mate, maintain a pair bond, and successfully fledge young in roadside habitats is an important avenue for further research.

Detailed studies of song frequency within individuals over time would address the question whether the observed frequency shift is a short-term, plastic response to noise or a more consistent phenomenon such as a dialectical change in noisy areas. Songbirds learn their songs from parents and neighbors, and some species can incorporate new songs into their repertoire throughout their lives (Hultsch and Todt 2004). Low-frequency components of songs will be more difficult to detect in noisy roadside habitats, and may not be learned by other neighboring birds (Slabbekoorn and Peet 2003, Brumm 2006). This could lead to the relatively rapid development of dialects with improved detectability in noise among populations occupying noisy roadside habitats (Slabbekoorn and den Boer-Visser 2006). A dialectical change may be more likely to occur at sites with constant, high levels of traffic noise such as those adjacent to freeways or in the center of cities.

In contrast to the frequency shift observed in the Grey Shrike-thrush, there was little evidence that the frequency of Grey Fantail song changed with increasing levels of traffic noise. This supports the hypothesis that birds with low-frequency signals will show a larger frequency shift in traffic noise than birds with higher frequency signals, because the former will experience greater acoustic interference from the low-frequency noise (Egan and Hake 1950, Warren et al. 2006). All bird species 
Fig. 3. The effect of traffic noise on the frequency of bird song (dominant frequency of the lowest tonal note). (A) Song of the Grey Shrike-thrush $(n=27)$; (B) song of the Grey Fantail $(n=22)$. Solid lines show the predicted relationships, dashed lines the $95 \%$ credible intervals, and circles the mean song frequency observed at each site.
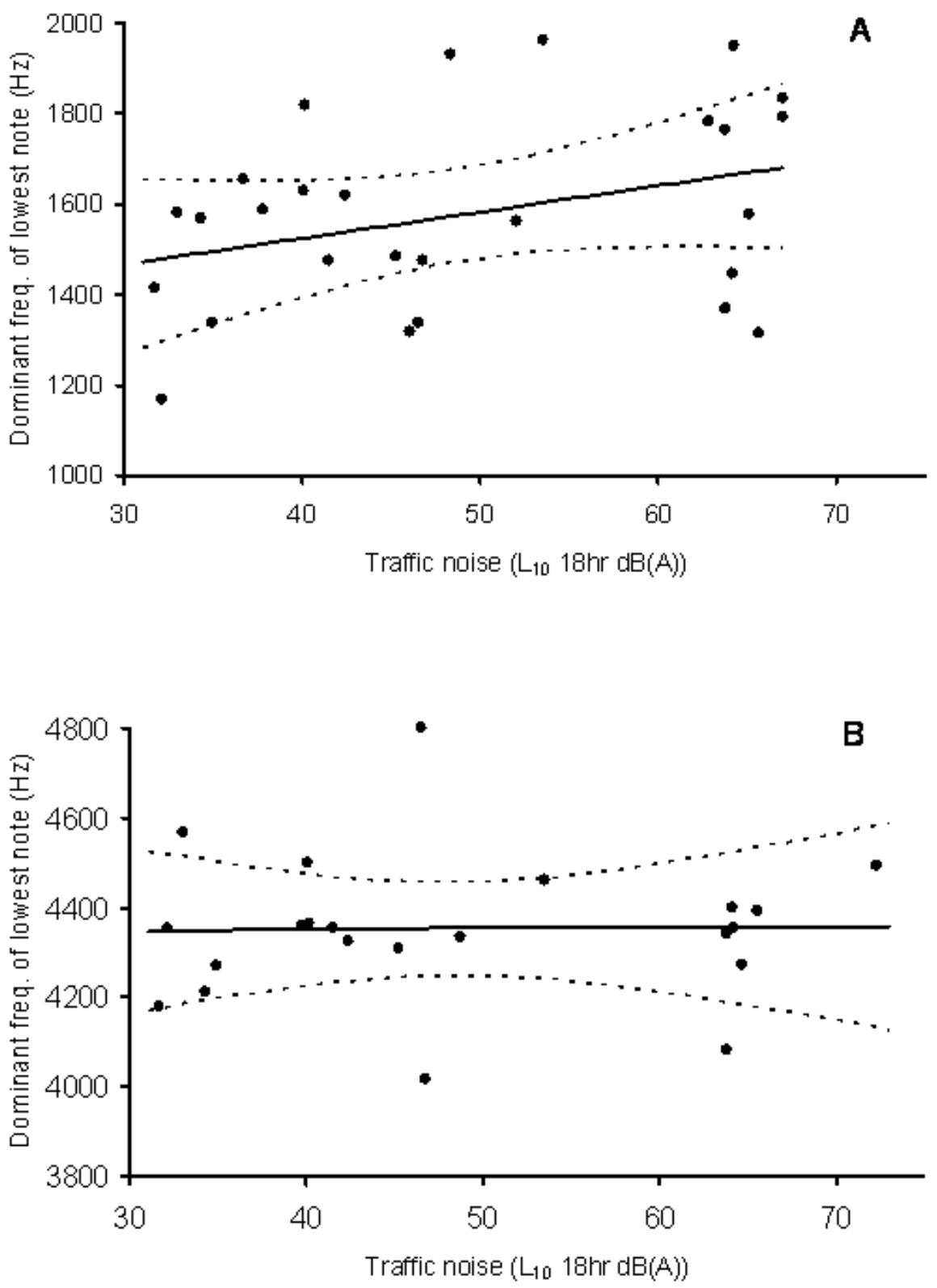
Table 2. Coefficients (Mean, SD, and 2.5th and 97.5th percentiles) of the variables included in the models of the probability of detecting the Grey Shrike-thrush on a visit to a site, as a function of traffic noise (Models 1 and 3) and traffic volume (Model 2), with the deviance information criterion (DIC) and receiveroperating characteristic curve (AUC) values for models 1 and 2. Models 1 and 2 include data from all 58 study sites, whereas Model 3 includes data from the 19 study sites in which traffic volume was $<200$ vehicles/d.

\begin{tabular}{llllllll}
\hline \hline & Variable & Mean & SD & $2.5 \%$ & $97.5 \%$ & DIC & AUC \\
\hline Model 1 & Constant & -0.609 & 0.710 & -2.19 & 0.258 & 102.7 & 0.76 \\
& Traffic noise & -0.114 & 0.066 & -0.28 & -0.041 & & \\
\multirow{2}{*}{ Model 2 } & Constant & -0.743 & 0.851 & -2.87 & 0.335 & 106.6 & 0.64 \\
& Traffic volume & -1.340 & 1.030 & -3.99 & -0.024 & & \\
\multirow{2}{*}{ Model 3 } & Constant & -0.116 & 0.428 & -0.87 & 0.819 & & \\
& Traffic noise & -0.122 & 0.063 & -0.26 & -0.007 & & \\
& & & & & \\
\hline
\end{tabular}

previously observed singing at a higher frequency in urban noise have songs in the frequency range below $3500 \mathrm{~Hz}$ (Slabbekoorn and Peet 2003, Fernández-Juricic et al. 2005, Slabbekoorn and den Boer-Visser 2006, Wood and Yezerinac 2006). In contrast, Grey Fantail song predominantly occupies the frequency band between 4000 and $7500 \mathrm{~Hz}$, with the dominant frequency of the lowest tonal note around 4300-4400 Hz.

Although acoustical energy in the spectral band of a signal makes the greatest contribution to masking, high-frequency signals can still suffer acoustic interference from low-frequency noise (Egan and Hake 1950), a phenomenon known as the upward spread of masking. Traffic noise masked the contact calls of the budgerigar, canary, and Zebra Finch, each with a dominant frequency around $3000 \mathrm{~Hz}$ during a controlled laboratory experiment (Lohr et al. 2003). Masking noise with the spectral distribution of traffic noise substantially reduced the distance over which the calls could be detected by conspecific birds. Signals higher than $4000 \mathrm{~Hz}$ may not experience important levels of acoustic interference from traffic noise; however, data on additional species are required to evaluate this further.

\section{Traffic noise, traffic volume, and the probability of detection}

Our results show clearly that both the Grey Shrikethrush and Grey Fantail were more likely to be detected on a visit to a site in quieter roadside habitats, although this effect was more pronounced for the Grey Shrike-thrush. As traffic-noise levels approached $60 \mathrm{~L}_{10} 18 \mathrm{~h} \mathrm{~dB}(\mathrm{~A}) \mathrm{SPL}$, the probability of encountering the target bird species on a visit to a site fell below 0.3 (Figs. 4 and 5). We did not detect $C$. harmonica at the 11 noisiest sites, at which traffic noise levels exceeded $67 \mathrm{~L}_{10} 18 \mathrm{~h} \mathrm{~dB}(\mathrm{~A}) \mathrm{SPL}$, and did not detect the Grey Fantail at the 8 noisiest sites (> $72.3 \mathrm{~L}_{10} 18 \mathrm{~h} \mathrm{~dB}(\mathrm{~A}) \mathrm{SPL}$ ). This finding is consistent with the hypothesis of Rheindt (2003) that birds with low-frequency signals will show a greater decline in abundance than those with highfrequency signals in habitats affected by traffic noise. Although we only have information on the probability of detecting each species on a visit to a site, rather than its actual presence or abundance, this probability is correlated with it presence and abundance. When a species occurs consistently at a high density, the probability of detection on a given visit will be high; when density is low and/or a site is only occupied sporadically, the probability of detection will be lower. Further surveys are required to determine, with confidence, the presence or 
Table 3. Coefficients (Mean, SD, and 2.5th and 97.5th percentiles) of the variables included in the models of the probability of detecting the Grey Fantail on a visit to a site, as a function of traffic noise (Models 1 and 3) and traffic volume (Model 2), with the deviance information criterion (DIC) and receiver-operating characteristic curve (AUC) values for models 1 and 2. Models 1 and 2 include data from all 58 study sites, whereas Model 3 includes data from the 19 study sites in which traffic volume was $<200$ vehicles/d.

\begin{tabular}{llllllll}
\hline \hline & Variable & Mean & SD & $2.5 \%$ & $97.5 \%$ & DIC & AUC \\
\hline Model 1 & Constant & -0.971 & 0.536 & -2.29 & -0.209 & 102.3 & 0.72 \\
& Traffic noise & -0.082 & 0.038 & -0.18 & -0.026 & & \\
\multirow{2}{*}{ Model 2 } & Constant & -0.952 & 0.546 & -2.30 & -0.171 & 106.1 & 0.66 \\
& Traffic volume & -1.050 & 0.573 & -2.40 & -0.155 & & \\
\multirow{2}{*}{ Model 3 } & Constant & -0.066 & 0.472 & -1.00 & 0.846 & & \\
& Traffic noise & -0.208 & 0.082 & -0.39 & -0.068 & & \\
& & & & & \\
\hline
\end{tabular}

absence of the target bird species at the study sites, and to quantify their density and breeding activity.

We were more likely to detect both the Grey Shrikethrush and Grey Fantail at roadside sites that had fewer passing vehicles. We did not observe the two species at sites at which traffic volumes exceeded 4000 and 13,700/d, respectively. However, traffic noise had a greater effect than traffic volume on the probability of detecting each species because the probability of detection declined more with traffic noise than with traffic volume. Furthermore, the predictive discrimination of the two traffic-noise models was superior to that of the traffic-volume models as indicated by their AUC values, and DIC values also favored the traffic-noise models as superior to the traffic-volume models. Our analysis at the 19 sites with fewer than 200 passing vehicles/ $\mathrm{d}$ demonstrated that the effect of traffic noise on the probability of detection remained strong when traffic volume was held constant. Thus, a variety of evidence supports traffic noise as having a more important effect than traffic volume on habitat suitability for the Grey Shrike-thrush and Grey Fantail.

There are a number of possible explanations for the observed results. First, traffic noise could be the real factor limiting populations of the Grey Shrikethrush and Grey Fantail in roadside habitats, and the observed decline in the probability of detection with increasing traffic volume might be spurious, i.e., an observation attributable to the high correlation between traffic volume and traffic noise. Alternatively, both traffic noise and traffic volume might reduce habitat suitability and affect the persistence of populations of the Grey Shrike-thrush and Grey Fantail in roadside habitats. The probability of a fatal collision between a bird and a passing vehicle is likely to increase with traffic volume (Oxley et al. 1974, Clevenger et al. 2003), thereby reducing survival rates of adults and/or juveniles in roadside habitats. If this reduction were sufficiently large and not offset by immigration, it could lead to local extinction. Mumme et al. (2000) investigated the population-level response of Florida Scrub Jays (Aphelocoma coerulescens) to an adjacent two-lane highway with a traffic volume of 500 vehicles/d. They concluded that roadside habitats were acting as a population sink in which deaths of breeding birds from road-kill outweighed the number of fledglings that survived to adulthood. A mathematical model developed by Jaeger et al. (2005) also supported traffic volume as an important determinant of the persistence of wildlife populations in habitats near roads.

Passing vehicles reflect sunlight by day and flash headlights at night (Goosem 2007); their movement may disturb birds, lower rates of occupancy, and/or 
Fig. 4. Predicted probability of detecting the Grey Shrike-thrush on a visit to a site as a function of (A) traffic noise and (B) traffic volume, across all 58 sites. Solid lines show the predicted relationships and dashed lines indicate the $95 \%$ credible intervals.

\section{Grey Shrike-thrush}
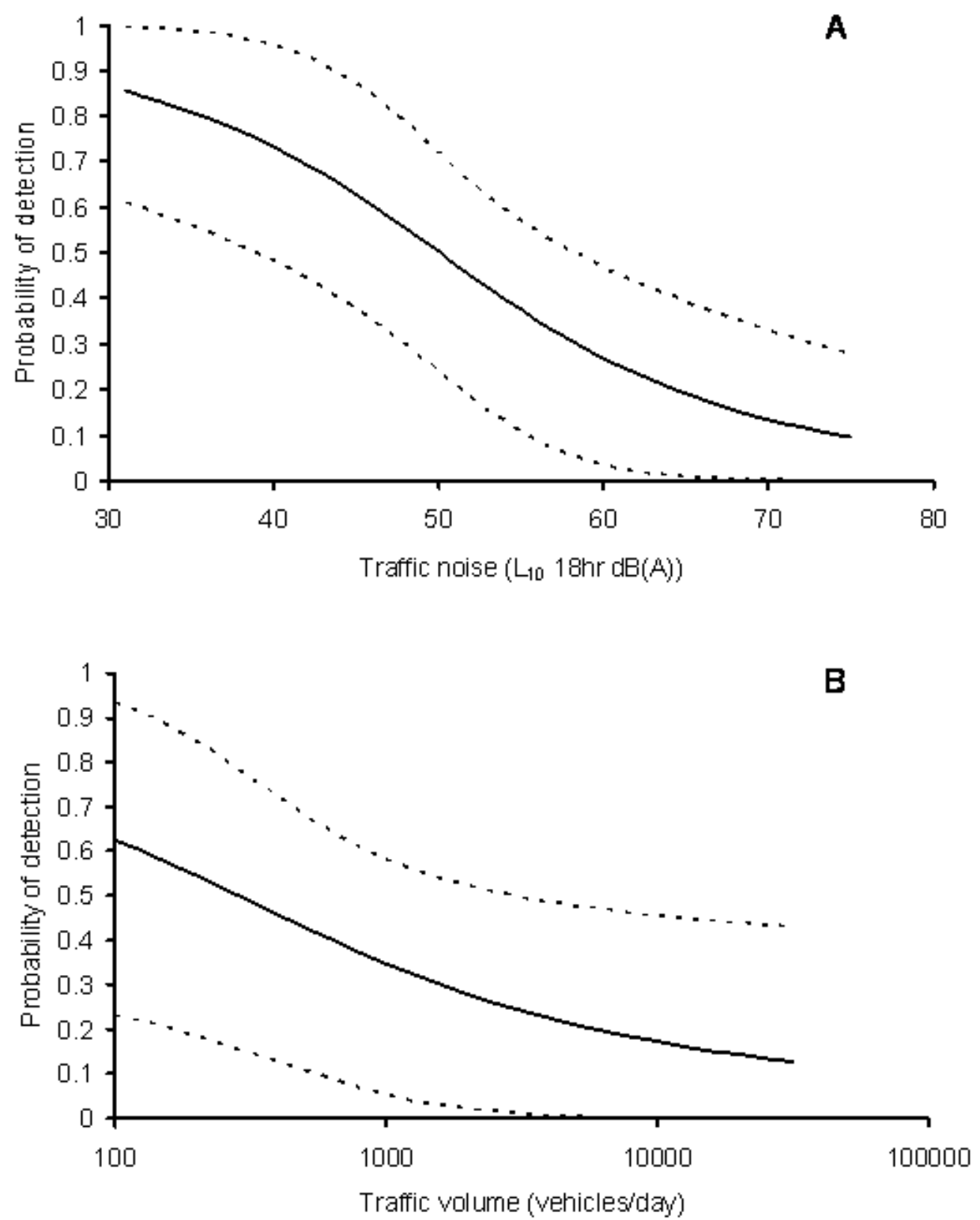
Fig. 5. Predicted probability of detecting the grey fantail on a visit to a site as a function of (A) traffic noise and (B) traffic volume, across all 58 sites. The solid lines show the predicted relationships and dashed lines the $95 \%$ credible intervals.
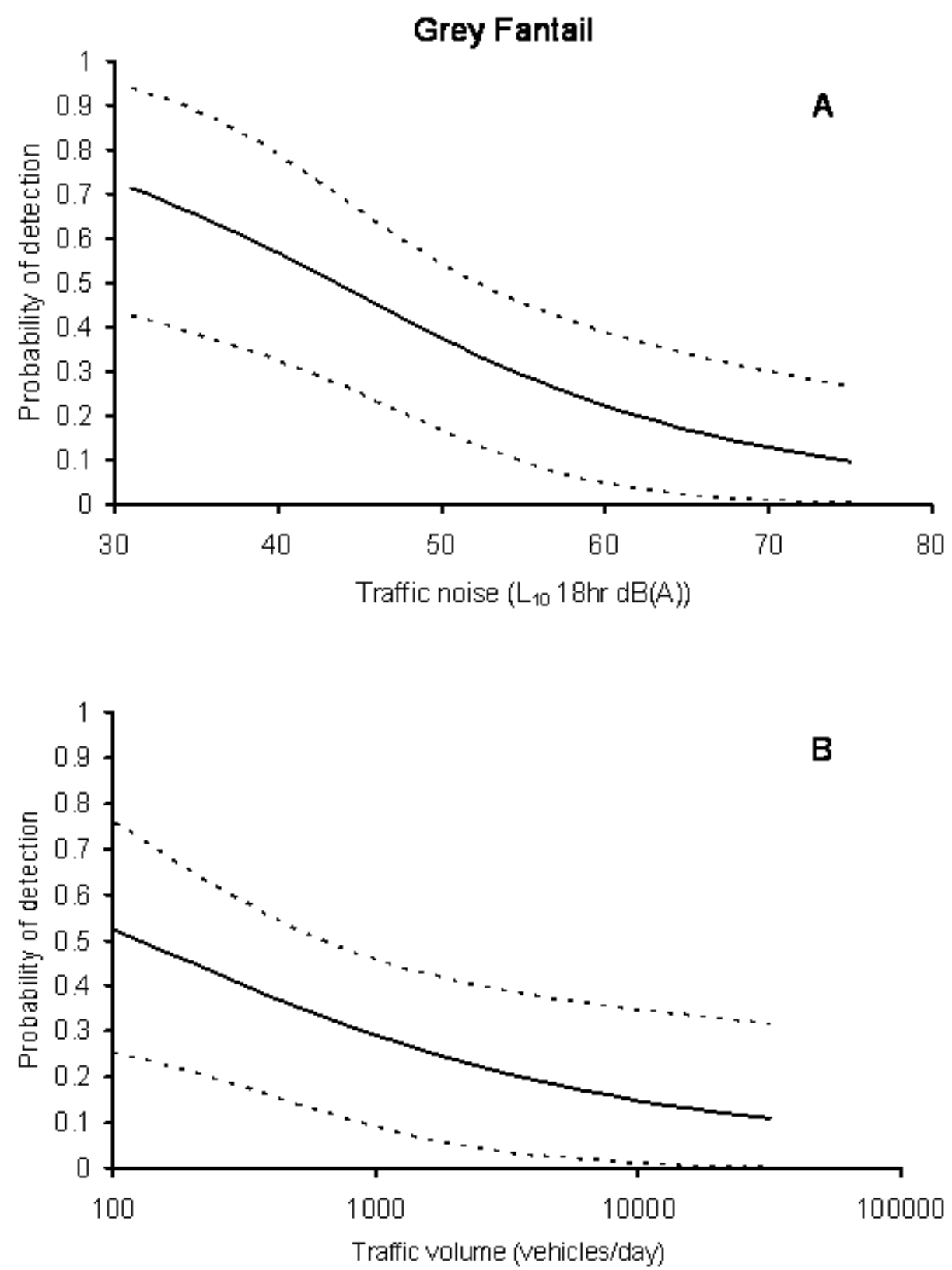
reduce breeding success at busy sites with high traffic volumes. However, it is difficult to separate the biological effect of visual disturbance from passing cars and the effect of disturbance by traffic noise, and only one other study has attempted to do so. Reijnen et al. (1995) assessed the effect of each variable while controlling for the other. They found that traffic noise reduced the density of more species of birds in woodlands than did the visibility of passing cars. Disturbance by pedestrians is known to interrupt activities such as foraging, nest building, and chick feeding in woodland and heathland birds, leading to reduced breeding success (e.g., Fernández-Juricic 2000, Murison et al. 2007), whereas disturbance by vehicles can reduce the breeding success of ground-nesting birds in open coastal habitats (e.g., McGowan and Simons 2006). However, the way in which birds of roadside habitats respond to disturbance by vehicles is uncertain.

A third explanation for our results is that traffic noise may have reduced the probability of detecting the Grey Shrike-thrush and Grey Fantail, not because the birds were less likely to be present at noisy sites, but because high levels of noise might have interfered with our ability to detect them when they were in fact present. However, this is unlikely given the narrowness of the roadside strips of vegetation and the active nature of the target bird species. And finally, sites with high noise levels, high traffic volumes, or both might have other characteristics that make them less suitable habitat for the target species. We found no important correlations between the habitat characteristics at a site and traffic-noise level or traffic volume, and accounted for the moderate correlations between landscape context and traffic noise and volume. Consequently, we think it unlikely that the decreasing probability of encountering the target bird species with increasing noise and traffic volume could be explained by differences in the habitat among sites.

\section{Impact of traffic noise on bird populations}

Traffic noise could affect bird populations in a number of ways. Acoustic interference from noise could hamper the detection of song by conspecifics, making it more difficult for birds to establish and maintain territories, attract mates, and/or maintain pair bonds (Reijnen and Foppen 1994, Habib et al. 2007, Swaddle and Page 2007). This, in turn, may reduce breeding success in noisy roadside habitats.
When begging for food, nestlings may need to call louder to elicit the desired response from their parents (Leonard and Horn 2005), thereby increasing the energetic cost of obtaining food and potentially decreasing fitness. High levels of traffic noise may also interfere with the detection of alarm calls such as those signaling the presence of predators, which could lead to higher rates of predation. There is evidence from studies in the northern hemisphere that traffic noise reduces the density of bird populations (Reijnen et al. 1995, 1996, Forman et al. 2002), but more research is needed to establish the generality of these patterns. These studies have inferred effects of traffic noise on bird populations from increases in the occurrence and/or density of birds with increasing distance from roads (Reijnen et al. 1995, 1996, Forman et al. 2002). However, such changes could be partially a result of other differences between roadside and road-distant habitats. Ours is the first study to investigate the effect of traffic noise on the occurrence of birds by locating all study sites next to roads; thus, holding distance from the road constant and reducing potentially confounding habitat differences between quiet and noisy sites. Therefore, it is an important addition to the literature on the responses of birds to traffic noise.

The results of our study present an interesting scenario for the Grey Shrike-thrush and Grey Fantail in roadside habitats on the Mornington Peninsula. As the traffic noise and traffic volume at a site increase, the chance of detecting the Grey Shrike-thrush declines substantially. However, the species can persist at roadside sites with trafficnoise levels up to $67 \mathrm{~L}_{10} 18 \mathrm{~h} \mathrm{~dB}(\mathrm{~A})$ SPL and traffic volumes up to $4000 / \mathrm{d}$, partly by increasing the frequency of its song to reduce acoustic interference. The higher singing Grey Fantail can persist at roadside sites with higher traffic-noise levels and higher traffic volumes than the Grey Shrike-thrush, and does not appear to change the frequency of its song with traffic noise. But, it too is excluded from roadside habitats with the highest levels of traffic noise and the greatest number of passing vehicles. Instead of, or in addition to, singing at a higher frequency, birds could reduce acoustic interference from traffic noise by singing at a higher amplitude (Brumm 2004), or by singing outside peak-traffic periods (Fuller et al. 2007). We did not measure song amplitude or assess temporal song patterns in our study, so cannot comment on whether the target species are using these strategies. Singing at a higher amplitude could have an 
energetic cost (Oberweger and Goller 2001), and may alert potential predators to the location of the singer. Songbirds probably use a combination of approaches to reduce acoustic interference in traffic-noisy habitats.

\section{CONCLUSION}

A range of evidence supports an important effect of traffic noise on birds in roadside habitats on the Mornington Peninsula, and there is also some evidence supporting an effect of traffic volume. The lower singing Grey Shrike-thrush sings at a higher frequency in traffic noise, but it appears that the higher singing Grey Fantail does not. If the Grey Fantail is not changing its song in the presence of noise, but is less likely to be found at sites with high traffic noise and traffic volume, this provides support for an effect of traffic volume on population persistence. Traffic noise and traffic volume may act in synergy to exclude birds from habitats next to noisy, busy roads. It will be difficult to elucidate their effects on bird populations experimentally; thus, comparative studies such as ours are particularly useful. Additional studies of other species with low-frequency and high-frequency songs will enable a meta-analysis to separate further the effect of noise from that of traffic volume.

Roadsides provide important habitat for birds in many countries around the world. They currently support a variety of threatened species (e.g., Adam and Robinson 1996, Mumme et al. 2000, Williford et al. 2007). Such species may be more vulnerable to the combined effects of traffic noise and passing vehicles than the common and widespread Grey Shrike-thrush and Grey Fantail. If roadside habitats are otherwise suitable for threatened species, this could be an argument for protecting them from noise and/or passing vehicles. But how do we do this? Installing sound barriers in urban habitats, as suggested by Slabbekoorn and Ripmeester (2008), would create barriers to movement for a variety of terrestrial animals, contributing to landscape fragmentation and the isolation of populations (Forman and Alexander 1998, Forman et al. 2003). Sound barriers are also expensive to construct and install, and contain substantial amounts of embodied energy. Alternatives to sound barriers include more careful consideration of the impact of traffic noise on animals that communicate acoustically when new roads are being planned, reducing traffic noise by changing road surfaces or decreasing the speed of vehicles, re-routing existing roads around important habitats for threatened species, or even closing roads during certain times of the year (Slabbekoorn and Ripmeester 2008). Since 1992, the seasonal closure of a road in Tilden Park, California has reduced roadkill of migrating California newts (Hilty et al. 2006), thereby setting a precedent such a management approach. Closing key roads during the breeding season could help to protect populations of threatened bird species from traffic noise and collision with vehicles at the time of year when they are most vulnerable. However, the effectiveness of such a strategy has yet to be examined for birds.

Responses to this article can be read online at: http://www.ecologyandsociety.org/voll4/iss 1/art29/ responses/

\section{Acknowledgments:}

We are grateful to VicRoads, the City of Casey, the City of Frankston, and the Mornington Peninsula Shire for data on traffic volumes, and to Michael McCarthy for assistance with data analysis. We thank Andrew Bennett, Henrik Brumm, and Murray Littlejohn for discussions, and Michael McCarthy for comments on the manuscript. This research was approved by the Deakin University Animal Welfare Committee, and supported by an ARC Discovery Grant to K. M. P., the Baker Foundation, and the Applied Environmental Decision Analysis research hub. This hub is funded by the Commonwealth Environment Research Facilities (CERF) programme, an Australian Government initiative that promotes world class, public-good research.

\section{LITERATURE CITED}

Adam, P., and D. Robinson. 1996. Negative effects of fuel-reduction burning on the habitat of the Greycrowned Babbler Pomastomus temporalis. Victorian Naturalist 113:4-9.

Anderson, D. R., K. P. Burnham, and W. L. Thompson. 2000. Null hypothesis testing: problems, prevalence, and an alternative. Journal of Wildlife Management 64:912-923. 
Antos, M. J., and J. G. White. 2004. Birds of remnant vegetation on the Mornington Peninsula, Victoria, Australia: the role of interiors, edges and roadsides. Pacific Conservation Biology 9:294-301.

Bambar, D. 1975. The area above the ordinal dominance graph and the area below the receiver operating characteristics graph. Journal of Mathematical Psychology 12:387-415.

Bee, M. A., and E. M. Swanson. 2007. Auditory masking of anuran advertisement calls by road traffic noise. Animal Behaviour 74:1765-1776.

Bellamy, P. E., R. F. Shore, D. Ardeshir, J. R. Treweek, and T. H. Sparks. 2000. Road verges as habitat for small mammals in Britain. Mammal Review 30:131-139.

Bennett, A. F. 1991. Roads, roadsides and wildlife conservation: a review. Pages 99-118 in D. A. Saunders and R. J. Hobbs, editors. Nature conservation 2: the role of corridors. Surrey Beatty and Sons, Chipping Norton, Australia.

Brumm, H. 2004. The impact of environmental noise on song amplitude in a territorial bird. Journal of Animal Ecology 73:434-440.

Brumm, H. 2006. City birds have changed their tune. Current Biology 16:R1003-R1004.

Brumm, H., and H. Slabbekoorn. 2005. Acoustic communication in noise. Advances in the Study of Behaviour 35:151-209.

Burnham, K.P., and D. R.Anderson. 2002. Model selection and multi-model inference: a practical information-theoretic approach. Springer-Verlag, New York, New York, USA.

Calder, W. 1986. Peninsula perspectives: vegetation on the Mornington Peninsula, Victoria. Jimaringle, Melbourne, Australia.

Clark, J. S. 2005. Why environmental scientists are becoming Bayesians. Ecology Letters 8:2-15.

Clevenger, A. P., B. Chruszcz, and K. E. Gunson. 2003. Spatial patterns and factors influencing small vertebrate fauna road-kill aggregations. Biological Conservation 109:15-26.

Collins, S. 2004. Vocal fighting and flirting: the functions of birdsong. Pages 39-79 in P. Marler and H. Slabbekoorn, editors. Nature's music: the science of birdsong. Academic Press/Elsevier, San Diego, California, USA.

Department of Transport Welsh Office. 1988. Calculation of road traffic noise. Her Majesty's Stationery Office, London, UK.

Dooling, R. 2004. Audition: can birds hear everything they sing? Pages 206-225 in P. Marler and H. Slabbekoorn, editors. Nature's music: the science of birdsong. Academic Press/Elsevier, San Diego, California, USA.

Egan, J. P., and H. W. Hake. 1950. On the masking pattern of a simple auditory stimulus. Journal of the Acoustical Society of America 22:622-630.

Fernández-Juricic, E. 2000. Local and regional effects of pedestrians on forest birds in a fragmented landscape. The Condor 102:247-255.

Fernández-Juricic, E., R. Poston, K. De Collibus, T. Morgan, B. Bastain, C. Martin, K. Jones, and R. Treminio. 2005. Microhabitat selection and singing behaviour patterns of male House Finches (Carpodacus mexicanus) in urban parks in a heavily urbanized landscape in the western U.S. Urban Habitats 3:49-69.

Fidler F., M. A. Burgman, G. Cumming, R. Buttrose, and N. Thomason. 2006. Impact of criticism of null-hypothesis significance testing on statistical reporting practices in conservation biology. Conservation Biology 20:1539-1544.

Ford, J. 1981. Evolution, distribution and stage of speciation in the Rhipidura fuliginosa complex in Australia. Ети 81:128-144.

Forman, R. T. T., and L. E. Alexander. 1998. Roads and their major ecological effects. Annual Review of Ecology and Systematics 29:207-231.

Forman, R. T. T., B. Reineking, and A. M. Hersperger. 2002. Road traffic and nearby grassland bird patterns in a suburbanizing landscape. Environmental Management 29:782-800.

Forman, R. T. T., D. Sperling, J. Bissonette, A. Clevenger, C. Cutshall, V. Dale, L. Fahrig, R. France, C. Goldman, K. Heanue, J. Jones, F. Swanson, T. Turrentine, and T. Winter. 2003. 
Road ecology: science and solutions. Island Press, Washington D.C., USA.

Fuller, R. A., P. H. Warren, and K. J. Gaston. 2007. Daytime noise predicts nocturnal singing in urban robins. Biology Letters 3:368-370.

Goosem, M. 2007. Fragmentation impacts caused by roads through rainforests. Current Science $\mathbf{9 3}$ (11).

Habib, L., E. M. Bayne, and S. Boutin. 2007. Chronic industrial noise affects pairing success and age structure of ovenbirds Seiurus aurocapilla. Journal of Applied Ecology 44:176-184.

Hanley J.A., and B. J. McNeil. 1982. The meaning and use of the area under a receiver operating characteristic (ROC) curve. Radiology 143:29-36.

Higgins, P. J., and J. M. Peter, editors. 2002. Handbook of Australian, New Zealand and Antarctic birds. Volume 6: Pardalotes to Shrikethrushes. Oxford University Press, Melbourne, Australia.

Higgins, P. J., J. M. Peter, and S. J. Cowling, editors. 2006. Handbook of Australian, New Zealand and Antarctic birds. Volume 7: Boatbill to starlings. Oxford University Press, Melbourne, Australia.

Hilty, J. A., W. Z. Lidicker, and A. M. Merenlender. 2006. Corridor ecology: the science and practice of linking landscapes for biodiversity conservation. Island Press, Washington D.C., USA.

Hultsch, H., and D. Todt. 2004. Learning to sing. Pages 80-107 in P. Marler and H. Slabbekoorn, editors. Nature's music: the science of birdsong. Academic Press/Elsevier, San Diego, California, USA.

Jaeger, J. A. G, J. Brennan, L. Fahrig, D. Bert, J. Bouchard, N. Charbonneau, K. Frank, B. Gruber, and K. T. von Toschanowitz. 2005. Predicting when animal populations are at risk from roads: an interactive model of road avoidance behavior. Ecological Modelling 185:329-348.

Johnson, D. H. 1999. The insignificance of statistical significance testing. Journal of Wildlife Management 63:763-772.
Katti, M., and P. S. Warren. 2004. Tits, noise, and urban bioacoustics. Trends in Ecology and Evolution 19:109-110.

Land Conservation Council. 1988. Statewide review. Land Conservation Council, Melbourne, Australia.

Leonard, M. L., and A. G. Horn. 2005. Ambient noise and the design of begging signals. Proceedings of the Royal Society B 272:651-656.

Lohr, B., T. F. Wright, and R. J. Dooling. 2003. Detection and discrimination of natural calls in masking noise by birds: estimating the active space of a signal. Animal Behaviour 65:763-777.

Lynch, J. F., W. J. Carmen, D. A. Saunders, and P. Cale. 1995. Use of vegetated road verges and habitat patches by four bird species in the central wheatbelt of Western Australia. Pages 34-42 in D. A. Saunders, J. L. Craig, and E. M. Mattiske, editors. Nature conservation 4: the role of networks. Surrey Beatty and Sons, Chipping Norton, Australia.

Marler, P. 2004. Bird calls: a cornucopia for communication. Pages 132-177 in P. Marler and H. Slabbekoorn, editors. Nature's music: the science of birdsong. Academic Press/Elsevier, San Diego, California, USA.

Marten, K., and P. Marler. 1977. Sound transmission and its significance for animal vocalization I. Temperate habitats. Behavioral Ecology and Sociobiology 2:271-290.

McCarthy, M. A. 2007. Bayesian methods for ecology. Cambridge University Press, Cambridge, UK.

McGowan, C. P., and T. R. Simons. 2006. Effects of human recreation on the incubation behavior of American Oystercatchers. The Wilson Journal of Ornithology 118:485-493.

Mornington Peninsula Shire. 2006. Unmade roads construction strategy. Mornington Peninsula Shire, Rosebud, Australia.

Mumme R. L., S. J. Schoech, G. E. Woolfenden, and J. W. Fitzpatrick. 2000. Life and death in the fast lane: demographic consequences of road mortality in the Florida Scrub-jay. Conservation Biology 14:501-512. 
Munguira, M. L., and J. A. Thomas. 1992. Use of road verges by butterfly and burnet populations, and the effect of roads on adult dispersal and mortality. Journal of Applied Ecology 29:316-329.

Murison, G., J. M. Bullock, J. Underhill-Day, R. Langston, A. F. Brown, and W. J. Sutherland. 2007. Habitat type determines the effects of disturbance on the breeding productivity of the Dartford Warbler Sylvia undata. Ibis 149 (Suppl. 1):16-26.

Oberweger, K., and F. Goller. 2001. The metabolic cost of birdsong production. Journal of Experimental Biology 204:3379-3388.

Oxley, D. J., M. B. Fenton, and G. R. Carmody. 1974. The effects of roads on small mammals. Journal of Applied Ecology 11:51-59.

Patricelli, G. L., and J. L. Blickley. 2006. Avian communication in urban noise: causes and consequences of vocal adjustment. The $A u k$ 123:639-649.

Pearce, J., and S. Ferrier. 2000. Evaluating the predictive performance of habitat models developed using logistic regression. Ecological Modelling 133:225-45.

Reijnen R., R. Foppen, and H. Meeuwsen. 1996. The effects of traffic on the density of breeding birds in Dutch agricultural grasslands. Biological Conservation 75:255-260.

Reijnen, R., and R. Foppen. 1994. The effects of car traffic on breeding bird populations in woodland. I. Evidence of reduced habitat quality for Willow Warblers (Phylloscopus trochilus) breeding close to a highway. Journal of Applied Ecology 31:85-94.

Reijnen, R., R. Foppen, C. ter Braak, and J. Thissen. 1995. The effects of car traffic on breeding bird populations in woodland. III. Reduction of density in relation to the proximity of main roads. Journal of Applied Ecology 32:187-202.

Rheindt, F. E. 2003. The impact of roads on birds: does song frequency play a role in determining susceptibility to noise pollution? Journal of Ornithology 144:295-306.

Saarinen, K., A. Valtonen, J. Jantunen, and S.
Saarnio. 2005. Butterflies and diurnal moths along road verges: Does road type affect diversity and abundance? Biological Conservation 123:403-412.

Sewell, S. R., and C. P. Catterall. 1998. Bushland modification and styles of urban development: their effects on birds in south-east Queensland. Wildlife Research 25:41-63.

Shochat, E., D. H. Wolfe, M. A. Patten, D. L. Reinking, and S. K. Sherrod. 2005. Tallgrass prairie management and bird nest success along roadsides Biological Conservation 121:399-407.

Slabbekoorn H., and A. den Boer-Visser. 2006. Cities change the songs of birds. Current Biology 16:2326-2331.

Slabbekoorn, H., and M. Peet. 2003. Birds sing at a higher pitch in urban noise. Nature 424:267.

Slabbekoorn, H., and E. A. P. Ripmeester. 2008. Birdsong and anthropogenic noise: implications and applications for conservation. Molecular Ecology 17:72-83.

Spiegelhalter, D. J., N. G. Best, B. P. Carlin, and A. van der Linde. 2002. Bayesian measures of model complexity and fit. Journal of the Royal Statistical Society: Series B 64:583-639.

Spiegelhalter, D., A. Thomas, N. Best, and D. Lunn. 2006. OpenBUGS user manual version 2.20. MRC Biostatistics Unit, Cambridge, UK.

Stevens, H. C., and D. M. Watson. 2005. Breeding biology of the Grey Shrike-thrush (Colluricincla harmonica). Ети 105:223-231.

Sun, J. W. C., and P. M. Narins. 2005. Anthropogenic sounds differentially affect amphibian call rate. Biological Conservation 121:419-427.

Swaddle, J. P., and L. C. Page. 2007. High levels of environmental noise erode pair preferences in Zebra Finches: implications for noise pollution. Animal Behaviour 74:363-368.

Trombulak, S. C., and C.A. Frissell. 2000. Review of ecological effects of roads on terrestrial and aquatic communities. Conservation Biology 14:18-30.

van der Ree, R. 2002. The population ecology of 
the Squirrel Glider (Petaurus norfolcensis) within a network of remnant linear habitats. Wildlife Research 29:329-340.

van der Ree, R, A. F. Bennett, and T. R. Soderquist. 2006. Nest-tree selection by the threatened Brush-tailed Phascogale (Phascogale tapoatafa) (Marsupialia: Dasyuridae) in a highly fragmented agricultural landscape. Wildlife Research 33:113-119.

Warren, P. S., M. Katti, M. Ermann, and A. Brazel. 2006. Urban bioacoustics: it's not just noise. Animal Behaviour 71:491-502.

Way, J. M. 1977. Roadside verges and conservation in Britain: a review. Biological Conservation 12:65-74.

White, J. G., M. J. Antos, J. A. Fitzsimons, and G. C. Palmer. 2005. Non-uniform bird assemblages in urban environments: the influence of streetscape vegetation. Landscape and Urban Planning 71:123-35.

Williford, D. L., M. C. Woodin, M. K. Skoruppa, and G. C. Hickman. 2007. Characteristics of roost sites used by Burrowing Owls (Athene cunicularia) wintering in southern Texas. Southwestern Naturalist 52:60-66.

Wintle, B.A., J. Elith, and J. M. Potts. 2005. Fauna habitat modelling and mapping: a review and case study in the Lower Hunter Central Coast region of NSW. Austral Ecology 30:719-738.

Wood, W. E., and S. M. Yezerinac. 2006. Song Sparrow (Melospiza melodia) song varies with urban noise. The Auk 123:650-659. 
Appendix 1. Song of the grey shrike-thrush Colluricincla harmonica, as shown in Fig. 1. File in .wav format - will run in a variety of programs including Windows Media Player, iTunes, and Adobe Audition. 
Appendix 2. Song of the grey fantail Rhipidura fuliginosa, as shown in Fig. 2. File in .wav format - will run in a variety of programs including Windows Media Player, iTunes, and Adobe Audition.

Please click here to download file 'appendix2.wav'. 